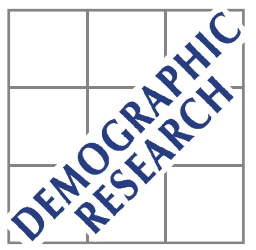

Demographic Research a free, expedited, online journal of peer-reviewed research and commentary in the population sciences published by the Max Planck Institute for Demographic Research Konrad-Zuse Str. 1, D-18057 Rostock · GERMANY www.demographic-research.org

DEMOGRAPHIC RESEARCH

VOLUME 25, ARTICLE 21, PAGES 667-694 PUBLISHED 30 SEPTEMBER 2011

http://www.demographic-research.org/Volumes/Vol25/21/

DOI: 10.4054/DemRes.2011.25.21

Research Article

\title{
Cohort change, diffusion, and support for gender egalitarianism in cross-national perspective
}

\section{Fred Pampel}

\section{(C) 2011 Fred Pampel.}

This open-access work is published under the terms of the Creative Commons Attribution NonCommercial License 2.0 Germany, which permits use, reproduction \& distribution in any medium for non-commercial purposes, provided the original author(s) and source are given credit. See http:// creativecommons.org/licenses/by-nc/2.0/de/ 


\section{Table of Contents}

1 Introduction 668

$\begin{array}{lll}2 & \text { Structural influences } & 669\end{array}$

$3 \quad$ Value shifts $\quad 670$

$\begin{array}{lll}4 & \text { Patterns of diffusion } & 671\end{array}$

5 Hypotheses $\quad 672$

6 Methods 674

$\begin{array}{lll}6.1 & \text { Data } & 674\end{array}$

6.2 Measures $\quad 674$

6.3 Models 676

$7 \quad$ Results $\quad 678$

$\begin{array}{lll}7.1 & 678 \\ 7.2 & \text { National variation } & 678\end{array}$

$\begin{array}{lll}7.2 & \text { Determinants } & 678\end{array}$

$\begin{array}{lll}7.3 & \text { Sensitivity checks } & 684\end{array}$

$\begin{array}{lll}8 & \text { Conclusion } & 686\end{array}$

$\begin{array}{ll}\text { References } & 689\end{array}$ 


\title{
Cohort change, diffusion, and support for gender egalitarianism in cross-national perspective
}

\author{
Fred Pampel ${ }^{1}$
}

\begin{abstract}
Arguments about the spread of gender egalitarian values through a population highlight several sources of change. First, structural arguments point to increases in the proportion of women with high education, jobs with good pay, commitment to careers outside the family, and direct interests in gender equality. Second, value-shift arguments contend that gender norms change with economic affluence among women and men in diverse positions - at all levels of education, for example. Third, diffusion arguments suggest that structural changes lead to adoption of new ideas and values supportive of gender equality by innovative, high-education groups, but that the new ideas later diffuse to other groups. This study tests these arguments by using International Social Survey Program surveys in 1988, 1994, and 2002 for 19 nations to examine gender egalitarianism across 85 cohorts born from roughly 1900 to 1984 . Multilevel models support diffusion arguments by demonstrating that the effects of education first strengthen with early adoption of gender egalitarianism and then weaken as other groups come to accept the same views. However, the evidence of a sequence of divergence and convergence in educational differences across cohorts appears most clearly for women in Western nations.
\end{abstract}

\footnotetext{
${ }^{1}$ Population Program, University of Colorado, Boulder CO 80309-0483. E-mail: fred.pampel@colorado.edu. This research received support from the National Science Foundation (Grant SES 0848623).
} 


\section{Introduction}

Under the broad term of the second demographic transition, demographers have described the wide-ranging changes that have occurred in living arrangements, gender roles, and childbearing (e.g., Lesthaeghe 2010). The changes encompass not only new behaviors involving sexual freedom, declining fertility, childbearing outside of marriage, and a greater variety of family forms (cohabitation, divorce, blended families, living alone) but also underlying value changes of individual autonomy, social equality, and tolerance of diversity (Lesthaeghe and Surkyn 1988). Central to the second demographic transition and to the broader liberalization of values are new roles for women and more favorable values, attitudes, and beliefs toward gender equality (or gender egalitarianism for short). The progress made over past decades toward the goal of widespread support for gender equality (Fischer and Hout 2006; Jackson 1998; Thornton and Young-DeMarco 2001) has affected most demographic processes, including fertility (Goldscheider, Oláh, and Puur 2010; Rindfuss, Brewster, and Kavee 1996), childlessness (Henz 2008), combining work and family responsibilities (Oláh and Bernhardt 2008), job segregation (Charles and Bradley 2002), and family relationships (Amato and Booth 1995; Kaufman 2000).

Demographers have also noted that a good part of the change in gender egalitarianism involves processes of cohort differentiation and replacement. The cohort approach to societal change follows a long tradition (Ryder 1965) in emphasizing the importance of the economic and ideational context at the time of a cohort's youth. Relatively stable values, attitudes, and beliefs that develop during youth and young adulthood endure over the later life course, and change comes from replacement of older cohorts raised decades ago with younger cohorts raised more recently. Numerous studies have demonstrated that differences in gender egalitarianism stem in large part from cohort membership (Brooks and Bolzendahl 2004; Firebaugh 1992; Inglehart and Norris 2003; Schnittker, Freese, and Powell 2003; Scott, Alwin, and Braun 1996).

In a recent article, Pampel (2011) evaluated several cohort-based explanations of increasing gender egalitarianism. Using data from the General Social Surveys of the United States and focusing on differences across cohorts born from 1900 to 1985, support was found for a diffusion theory that predicts changes in the socioeconomic distribution as well as the level of gender egalitarianism. More limited support was found for competing theories that emphasize the importance of either structural change in levels of female education and labor force participation or broad cultural changes in values affecting all education and labor force groups. The findings build on demographic approaches to social change that emphasize cohort influences, but also, in focusing on diffusion, offer a more precise description of how cohort change occurs. 
The examination of cohort changes in one nation can offer only modest support for the diffusion arguments, however. European nations show diversity in attitudes toward gender equality (Alwin, Braun, and Scott 1992), with Norway, Sweden, and the Netherlands having stronger support for working mothers than nations of central, southern, and eastern Europe (Treas and Widmer 2000). The goal of this study is to extend tests of theories of cohort change in gender egalitarianism to include European nations and thereby offer a more complete evaluation of the theories as well as their international scope. The next sections describe the competing explanations of changing gender egalitarianism as presented by Pampel (2011) and then present new tests using comparative data for 19 European or European-heritage nations from the International Social Survey Program.

\section{Structural influences}

Changes in gender egalitarianism may occur through increases in the proportion of women with high education, good-paying jobs, and commitment to careers outside the family. As jobs shift from industrial economies to post-industrial service and knowledge economies and the demand of employers for female workers rises (Huber 1990), the labor force becomes more gender integrated. Tertiary educational opportunities for women increase, as does access to professional and managerial jobs once filled by men. Trends toward later marriage, fewer children, and more divorce reinforce education and job changes (Brooks and Bolzendahl 2004). At the societal level, then, the composition of the population changes in ways that foster gender egalitarianism.

An interest-based mechanism underlies arguments about the economic stake that nontraditional women have in gender equality (Bolzendahl and Myers 2004; Huber and Spitze 1981; Plutzer 1988). Because women with high education and special job skills gain the most from equal treatment and suffer the most from gender discrimination, they tend to have more egalitarian attitudes. To a lesser extent, men may also benefit economically from more egalitarian treatment and higher pay for working spouses, children, and relatives (Smith 1985; Zuo and Tang 2000). Indeed, studies have found that men have more egalitarian attitudes when they are part of a dual-earning couple (Cha and Thébaud 2009). In contrast, women with more traditional commitments to family and children will have fewer incentives to adopt new attitudes (Glass 1992; Kane and Sanchez 1994). They may even strengthen their adherence to traditional attitudes, which widens gender-based political cleavages (Plutzer 1988). Despite structural change, then, the continued dependence of some women on men maintains 
inegalitarian views (Baxter and Kane 1995). Also, men's interests may partly lie in gender inequality that reinforces their advantages in job opportunities and income.

Much of the change in gender egalitarianism related to structural position occurs through cohort replacement (Brewster and Padavic 2000; Brooks and Bolzendahl 2004; Firebaugh 1992). New educational, work, and job opportunities for women-and new values, attitudes, and beliefs - emerge among younger generations. The positions and roles of older cohorts change less, as do their more traditional attitudes. The replacement of older cohorts by younger cohorts who are more affected by recent structural changes in education and work leads to greater prevalence of gender egalitarianism. If those with socioeconomic characteristics, such as high education, that predispose them toward egalitarian views become a steadily larger part of the population, particularly among younger generations, then the level of gender egalitarianism will rise as well, even as inegalitarian values persist among older cohorts.

\section{Value shifts}

Arguments focusing on broad shifts in values suggest that gender norms develop, at least in part, independently of social structural position. Women and men in varied positions of a society - those with and without advanced education, for example - come to adopt more egalitarian attitudes with material prosperity. Broad changes in values do not erase attitudinal differences, but they raise egalitarianism similarly across diverse social positions and groups. Thus, studies have found a pervasive trend toward endorsement of gender equality in the United States since the 1960s (Rindfuss, Brewster, and Kavee 1996; Thorton and Young-DeMarco 2001). Support for gender equality grew among men as well as women (Bolzendahl and Myers 2004), and among active Protestants with conservative religious views as well as less religious and liberal groups (Petersen and Donnenwerth 1998).

The pervasive value shift raises questions about why groups in different positions and with different interests similarly become more egalitarian. Inglehart and Norris (2003) argued that economic prosperity and material security foster a broad cultural shift toward postmaterialist, quality-of-life values that emphasize equality, selfexpression, and individualism (also see Inglehart and Baker 2000). Jackson (1998) argued that the shift of economic and political power from households to business and government institutions in modern societies tends to erode family authority, communal obligations, and traditional beliefs and to weaken the incentives and means needed to maintain men's power over women. Given the pervasiveness of the change, diverse social groups tend to respond with stronger support for gender equality. 
These arguments treat interests in broad terms (Inglehart 1989). Despite the existence of inequality, societal economic prosperity and material security tend to affect norms and values widely. Interests thus remain a key source of egalitarian values but relate to the larger social and economic context of value change rather than to the particular positions of individuals. However, these egalitarian values tend to change generationally. Adoption of new values commonly occurs during adolescence and young adulthood, and cohorts tend to retain these values throughout later adulthood. Inglehart (1989) argued that cohorts raised during the post-World War II decades of material prosperity and economic security widely adopted postmaterialist values. In support, Inglehart and Norris (2003:46) found that generation more strongly predicts egalitarian attitudes than does sex, class, or education.

The value-shift arguments thus differ fundamentally from structural arguments in accounting for rising gender egalitarianism. They posit that, at least among post-World War II cohorts, egalitarian attitudes increase across diverse sociodemographic groups. While women in nontraditional positions maintain more egalitarian views than others, changes in gender egalitarianism occur widely in postindustrial societies.

\section{Patterns of diffusion}

Diffusion arguments highlight a sequence of influences in which the early stages of change mostly involve the attitudes of educated and working women, those in nontraditional positions and with the strongest interests in gender equality. At later stages of change, egalitarianism diffuses vertically from high status, nontraditional innovators to lower status, less innovative, and more traditional groups (Poole and Zeigler 1981). Thus, effects of the determinants first strengthen as innovative groups with strong interests in gender equality adopt egalitarian views and set themselves apart from other groups. The effects of the determinants then weaken as gender egalitarian views diffuse to larger parts of the population (Fischer and Hout 2006).

In support, several studies describe a process of catching up in which formerly wide attitude differences narrow with the spread of new values to less innovative groups. Mason and $\mathrm{Lu}$ (1988) found growth in gender egalitarianism among most sociodemographic groups in the United States from 1977 to 1985, except for collegeeducated women, who already had high gender egalitarianism. Bolzendahl and Myers (2004) found that as most people come to accept gender egalitarian goals, individual determinants of attitudes toward women's participation in the public sphere have declining influence. Fischer and Hout (2006) found widening and narrowing by age and city residence in measures of approval for working women from 1936 to 2000. 
These changes in relationships are consistent with general diffusion arguments. Montgomery and Casterline (1993) defined diffusion as the influence of adoption of innovative ideas and behaviors by some individuals on the likelihood of adoption by others. Diffusion often first occurs horizontally among higher socioeconomic groups because these groups tend to be the most innovative and have communication networks across structurally equivalent positions (Strang and Meyer 1993). Advanced education, for example, fosters gender egalitarianism at the early stage of the epidemic by promoting tolerance (Weil 1985), openness to new ideas (Rogers 2003), and cognitive skills needed to better evaluate new ideas (Ohlander, Batalova, and Treas 2005). Vertical diffusion often follows, as lower ranking groups adopt the practices and ideas of more prestigious groups (Fischer 1978; Strang and Soule 1998). Interests or the relative advantage of adoption play a role in adoption of innovations, at least initially (Rogers 2003:229). Later, acceptance of new ideas may become self-sustaining after adopters reach a critical mass (Rogers 2003:343). At that point, adoption by less innovative groups requires less risk and boldness.

The arguments predict that the early adoption of gender egalitarianism by more advantaged groups initially involves innovation that strengthens socioeconomic differences, but the vertical diffusion of the values to other groups later reduces socioeconomic differences. However, women who benefit the most from gender equality will more quickly adopt new attitudes than men (Ciabattari 2001). The diffusion of gender egalitarianism may occur for men but not as quickly or to the same extent as for women.

\section{Hypotheses}

The hypotheses focus neither on overall changes in support for gender egalitarianism nor on group differences in attitudes - topics that have been well studied. Rather, they focus on the combination of the two topics: on whether groups change their attitudes at different rates and exhibit divergence in views followed by convergence. Further, the hypotheses focus on cohort differences in gender egalitarianism. As noted earlier, cohort replacement is a crucial component of change in gender egalitarianism; the precise pattern of cohort change is less well understood, and each hypothesis posits a different mechanism of cohort differentiation.

In differentiating between the theoretical arguments, the hypotheses focus largely on education. Although other sociodemographic characteristics, such as employment, income, and family status, strongly influence gender egalitarianism, education has special value in making comparisons across cohorts. Because education is determined early in life, it relates directly to the past experiences of cohorts. Education measured at 
age 75 for older cohorts likely differs little from education if it were measured 50 years earlier at age 25 . In contrast, current employment, income, and family status of a cohort will differ enormously from their levels decades ago. Given that older cohorts lack data on other indicators for earlier ages and periods, the stability of education over the later life course makes it most suited for specifying and testing the hypotheses. Of course, education also has value because it relates closely to other components of socioeconomic background and attainment. With this in mind, the competing hypotheses are as follows:

H1: Changes in the educational composition of cohorts account for cohort increases in gender egalitarianism. Consistent with structural arguments, the hypothesis implies that differences in gender egalitarianism across groups with varied levels of education (and indirectly with varied work and income opportunities that follow from education) are maintained across cohorts, but that low-education groups decline in size relative to groups with high education.

$\mathrm{H} 2$ : Changes across cohorts in gender egalitarianism occur similarly for educational groups. Consistent with value-shift arguments, the hypothesis implies that differences in views across innovative groups with high education and more traditional groups with low education persist but that gender egalitarianism rises across cohorts for all educational groups.

H3: Changes across cohorts first affect innovative groups with high education, thus strengthening the effects of education on gender egalitarianism and creating divergence in views, but the changes later affect less-educated groups, thus weakening the differentiating effects of education and creating convergence in views. Consistent with diffusion arguments, the hypothesis also implies that the changes occur more quickly and strongly for women than men.

Previous studies have analyzed consecutive cross-sectional surveys in the United States (Bolzendahl and Myers 2004; Brewster and Padavic 2000; Carter, Corra, and Carter 2009; Mason and Lu 1988; Rindfuss, Brewster, and Kavee 1996; Spitze and Huber 1980), and several examine the influence of cohort on attitudes (Brooks and Bolzendahl 2004; Schnittker, Freese, and Powell 2003; Wilkie 1993). Several others have examined attitudinal differences across nations (Scott, Alwin, and Braun 1996; Treas and Widmer 2000). Besides the work of Pampel (2011), however, no study has fully tested the predictions about nonlinear strengthening and weakening across cohorts of the effects of education. 


\section{Methods}

\subsection{Data}

The International Social Survey Program (ISSP 2011), a collaboration of nations conducting annual surveys for probability samples of their populations, has completed three sets of surveys on gender roles. Eight nations participated in the 1988 surveys; 24 in the 1994 surveys; and 35 in the 2002 surveys. To examine cohort effects, however, only nations with data for at least two of the years are used. ${ }^{2}$ Counting separate surveys for East and West Germany and for Great Britain and Northern Ireland, that leaves 22 nations or national regions. However, all but three nations are European in location or heritage. The exceptions-Israel, Japan, and the Philippines-differ enough from the others in geographic location, history, and culture to exclude from the analysis. Of the remaining 19 nations, seven have surveys for all three years. Because of the longer time span and greater ability to isolate cohort effects, surveys for these seven nations-West Germany, Great Britain, the United States, Austria, Hungary, Ireland, and the Netherlands - are central to the analysis. Of the other 12 nations with at least two time points, six are former communist nations of eastern Europe (East Germany, Czech Republic, Slovenia, Poland, Bulgaria, and Russia), and six are Western nations (Australia, Northern Ireland, Italy, Norway, Sweden, and New Zealand).

\subsection{Measures}

All three sets of ISSP surveys ask about agreement with statements concerning gender roles and equality. Despite diverse nations in the sample and the diverse domains of gender equality covered by the questions, the 12 items appear to reflect an overall dimension of support for gender equality and form a reliable scale (Cronbach's alpha of .80 ). The items in abbreviated form are as follows: (1) A working mother can establish just as warm and secure a relationship with her children as a mother who does not work; (2) A preschool child is likely to suffer if his or her mother works; (3) Family life suffers when the woman has a full-time job; (4) A job is all right, but what most women really want is a home and children; (5) Being a housewife is just as fulfilling as working for pay; (6) Having a job is the best way for a woman to be an independent person; (7) Both the husband and wife should contribute to the household income; (8) A husband's job is to earn money; a wife's job is to look after the home and family; (9) A

\footnotetext{
${ }^{2}$ Spain has data for 1994 and 2002, but it lacks measures of education in 1994 and, given the importance of this variable, effectively has data for only one year.
} 
woman should work after marrying and before there are children; (10) A woman should work when there is a child under school age; (11) A woman should work after the youngest child starts school; and (12) A woman should work after the children leave home. With all items coded so that high scores indicate support for gender equality and standardized to have a mean of zero and a standard deviation of one, a standardized scale is created from summing the items.

The lack of nuance in these items means that they miss important components of views about gender equality (Brewster and Padavic 2000; Mason and Lu 1988), and the items relate to work/family issues for women rather than to politics, earnings, discrimination, task sharing at home, or men's roles. Goldscheider, Oláh, and Puur (2010) argue that attitudes about public equality relating to work and politics change at different rates than components relating to private or family equality. Also, Kane and Kyyrö (2001) make a distinction between attitudes that, on one hand, promote ideological refinement but maintain individualism and largely reproduce inequality and those that, on the other hand, espouse group-based remedies to fundamentally restructure relations of inequality between men and women's roles. The items studied here relate to private more than public gender equality and more to individual than group-based remedies for gender inequality. Still, items such as these are commonly used in national and cross-national surveys and meaningfully summarize variation in attitudes toward certain forms of gender equality across as well as within nations. The reliability of the scale used here plus the consistent relationships observed in previous studies between gender equality items and socioeconomic characteristics and period trends suggest the value of the items.

Cohort measures single years of birth and ranges from 1900 (or earlier) to 1984 (or later). Year has three values: 1988, 1994, and 2002. To avoid exact dependency with cohort and year, age is grouped into seven categories: $18-25,26-35,36-45,46-55,56-$ $65,66-75$, and $76+$. Given the focus on cohort changes and characteristics determined early in life and largely stable thereafter, the key determinants are gender, mother's work, and especially, education. For gender, females are coded 1. A mother worked measure equals 1 for respondents whose mother ever worked for pay for at least one year after the birth of a child and before the child turns 14 .

The education measure is based on years of schooling completed, which is recoded to have a minimum of 8 and a maximum of 20. Years completed is more comparable across nations than measures based on the highest degree obtained. However, several nations ask only about highest degree, and in nations that do ask about years of schooling, some respondents report only their highest degree. Given that the two measures have a high correlation of .62, the degree measure is used to impute values when data for the years completed measure are missing. However, some nations in the early years truncate the measure. (For example, in 1988 Great Britain reported a 
minimum of 10 and maximum of 14.) To adjust for somewhat different scales, education also can be standardized within nations and years. That is, each individual's education is centered on the mean of the nation and year and divided by the standard deviation of the nation and year so that all nations and years have the same mean of 0 and standard deviation of 1 . Standardized education can account for differences in gender egalitarianism within nations, but not between nations.

The remaining variables reflect current rather than past characteristics. Although less relevant to early cohort experiences, these variables affect gender egalitarianism. A set of five dummy variables measures employment status: (1) full-time worker or student; (2) part-time worker; (3) unemployed; (4) homemaker; and (5) retired. Dummy variables measure marital status by spouse employment status: unmarried and noncohabiting persons serve as the omitted group; married or cohabiting persons whose spouse is not employed define one dummy variable; and married or cohabiting persons whose spouse is employed define a second dummy variable. A measure of family income differs in wording across nations, with some nations asking about net income and others asking about gross income. With the national currency differing as well, it is necessary to create a standardized family income score that has a mean of 0 and standard deviation of 1 for each nation and year. This measure can affect differences within but not between nations. Two other measures, occupation and urban residence, are measured too differently across nations and years to use in the models.

\subsection{Models}

A cross-classified random-effects model for the analysis of age, period, and cohort effects (Yang and Land 2006) is well suited to testing hypotheses about cohort changes in the effects of education. The model treats cohort and cohort squared plus control variables as determinants of the outcome measures of gender egalitarianism (GE). The individual data are nested within cells created by the cross-classification of period and age group. The use of cohort quadratic terms with five-year age groups and the two or three survey years eliminates the dependency of cohort on age and period. Following Yang and Land (2006), the Level 1, or within-cell, model takes the following form:

$$
\begin{aligned}
G_{i j k}= & \beta_{0 j k}+\beta_{1 j k} \cdot \text { Cohort }_{i j k}+\beta_{2 j k} \cdot \text { Cohort }_{i j k}^{2}+\beta_{3 j k} \cdot \text { Education }_{i j k} \\
& +\beta_{4 j k} \cdot \text { Cohort }_{i j k} \cdot \text { Education }_{i j k}+\beta_{5 j k} \cdot \text { Cohort }_{i j k}^{2} \cdot \text { Education }_{i j k} \\
& +\sum \beta_{m j k} \cdot X_{m i j k}+e_{i j k},
\end{aligned}
$$


where $i$ refers to individuals within $j$ age groups and $k$ years, $X$ to $m$ control variables (including dummy variables for nation), and $e$ is a normally distributed error with a mean of 0 and variance of $\sigma^{2}$. The product terms allow for nonlinear changes in the effect of education across cohorts. With the intercept assumed to vary randomly, the Level 2, or between-cell, model takes the following form:

$$
\beta_{0 j k}=\gamma_{0}+u_{0 j}+v_{0 k}
$$

where $\gamma_{0}$ is the model intercept or adjusted mean outcome; $u_{0 j}$ is the residual random effect of age group $j$ on $\beta_{0 j k}$ averaged over all periods, which is assumed to be normally distributed with mean 0 and variance $\tau_{u}$; and $v_{0 k}$ is the residual random effect of period $k$ on $\beta_{0 j k}$ averaged over all ages, which is assumed to be normally distributed with mean 0 and variance $\tau_{v}$. The model thus allows for estimation of cohort effects on GE with random-effects controls for age group and year. ${ }^{3}$ The slope coefficients $\beta_{1}$ through $\beta_{m}$ are treated as fixed. With all variables centered, the crossed random-effects estimates come from xtmixed in Stata 11.0. ${ }^{4}$

The three hypotheses translate into predictions about the multilevel coefficients. The structural position hypothesis (H1) predicts that because changing population composition accounts for increases in GE, cohort will have little influence net of the individual determinants (i.e., $\beta_{1}=\beta_{2}=\beta_{4}=\beta_{5}=0$ ). The value-change hypothesis (H2) predicts that because of the widespread increase in GE among all groups, cohort will nonlinearly increase the intercept or level of GE (i.e., $\beta_{1}>0$ and $\beta_{2}<0$, but $\beta_{4}=\beta_{5}=0$ ). The diffusion hypothesis (H3) predicts that the slopes of education, not just the GE level, will change across cohorts as favorable views first emerge among innovative groups with direct interests in equality and then diffuse to other groups. This change in relationships across cohorts implies that the key determinants of GE interact with cohort and cohort squared (i.e., $\beta_{4}>0$ and $\beta_{5}<0$ ). The interactions, however, should be stronger for females than for males.

\footnotetext{
${ }^{3}$ Random effects might also be estimated for nations in models with three levels. The number of nations available for analysis, however, falls well below that needed to obtain reliable estimates (approximately 30 , as a rough rule of thumb). I use fixed effects for nations instead.

${ }^{4}$ The xtmixed program does not allow for use of weights, but checks using regression show that weighting changes the results only slightly.
} 


\section{Results}

\subsection{National variation}

Table 1 lists the means by nation and year for the standardized GE scale. The means are higher in 2002 than in earlier years, and all nations show increasing GE over time. For example, the mean for West Germany rises from -.43 in 1988 to -.15 in 1994 and to .26 in 2002, while the mean for the United States rises by less, from 0.04 in 1988 to 0.18 in 1994 and to 0.26 in 2002. For comparisons across nations in 2002, the most recent year, East Germany, Norway, and Sweden have the highest mean values, while Australia, Hungary, Poland, Bulgaria, Russia, and New Zealand have the lowest means values. Although there are exceptions, the former-Communist nations of eastern Europe generally score lower than the Western nations.

As shown in Table 1, there are 8 nations in 1988, 19 in 1994, and 18 in 2002; pooling these data gives 45 nation-years. Most of the variance in the GE scale exists within rather than between nations and years, however. Some additional runs allow for calculation of intraclass correlations. For the group of seven nations with three time points, the between-nation and year variance in the GE scale equals $7.1 \%$ of the total; for all nations combined, including those with two time points, the between-nation and year variance in the GE scale equals $11.7 \%$ of the total.

\subsection{Determinants}

Table 2 shows effects of the determinants of the GE scale with random-effects controls for year and the age categories, and with fixed-effects or dummy variable controls for nation. Consider first the top panel of results for women. The initial models include only the seven nations with three time points. In the first model, GE increases with cohort, but the increase tends to level off for the cohorts born most recently. These coefficients indicate increasing GE when controlling for compositional changes, and thus favor the value-change argument over the structural-position argument. In addition, the random effects for year and the age categories show higher GE in later years and for middle-age persons. The other variables have expected relationships that match the findings of previous literature: Women with working mothers, no marital or cohabiting partner (the omitted category), high education, high family income, and full-time work (the omitted employment category) have higher GE values. 
Table 1: Mean scores on gender egalitarianism scale and sample sizes by nation and year

\begin{tabular}{|c|c|c|c|c|c|c|c|}
\hline Nation & 1988 & 1994 & 2002 & Nation & 1988 & 1994 & 2002 \\
\hline \multirow[t]{2}{*}{ 1. Australia } & & -0.14 & 0.03 & 11. Netherlands & -0.21 & 0.12 & 0.29 \\
\hline & & 1,778 & 1,341 & & 1,635 & 1,905 & 1,194 \\
\hline \multirow[t]{2}{*}{ 2. West Germany } & -0.43 & -0.15 & 0.26 & 12. Norway & & 0.18 & 0.53 \\
\hline & 2,981 & 2,320 & 930 & & & 2,015 & 1,462 \\
\hline \multirow[t]{2}{*}{ 3. East Germany } & & 0.90 & 0.95 & 13. Sweden & & 0.52 & 0.74 \\
\hline & & 1,096 & 427 & & & 1,269 & 1,078 \\
\hline \multirow[t]{2}{*}{ 4. Great Britain } & -0.03 & 0.18 & 0.20 & 14. Czech Republic & & -0.07 & 0.14 \\
\hline & 1,307 & 980 & 1,953 & & & 1,022 & 1,284 \\
\hline \multirow[t]{2}{*}{ 5. Northern Ireland } & & 0.17 & 0.19 & 15. Slovenia & & -0.07 & 0.33 \\
\hline & & 647 & 977 & & & 1,029 & 1,093 \\
\hline \multirow[t]{2}{*}{ 6. US } & 0.04 & 0.18 & 0.26 & 16. Poland & & -0.47 & 0.05 \\
\hline & 1,396 & 1,445 & 1,170 & & & 1,592 & 1,245 \\
\hline \multirow[t]{2}{*}{ 7. Austria } & -0.45 & -0.06 & 0.17 & 17. Bulgaria & & -0.25 & 0.01 \\
\hline & 948 & 931 & 1,997 & & & 1,109 & 990 \\
\hline \multirow[t]{2}{*}{ 8. Hungary } & -0.40 & -0.58 & -0.07 & 18. Russia & & -0.64 & -0.08 \\
\hline & 1,731 & 1,500 & 1,022 & & & 1,996 & 1,795 \\
\hline \multirow[t]{2}{*}{ 9. Italy } & -0.22 & -0.09 & & 19. New Zealand & & -0.05 & -0.02 \\
\hline & 1,028 & 1,018 & & & & 1,044 & 1,024 \\
\hline \multirow[t]{2}{*}{ 10. Ireland } & -0.23 & 0.03 & 0.22 & Total & -0.26 & -0.05 & 0.20 \\
\hline & 1,004 & 938 & 1,178 & & 12,030 & 25,634 & 22,160 \\
\hline
\end{tabular}


Pampel: Cohort change, diffusion, and support for gender egalitarianism in cross-national perspective

Table 2: Unstandardized coefficients and $t$ values for multilevel models of gender egalitarianism with year and age group random effects

\begin{tabular}{|c|c|c|c|c|c|c|c|c|c|}
\hline & \multicolumn{4}{|c|}{7 Nations, Three Years } & \multicolumn{5}{|c|}{19 Nations, Two or Three Years } \\
\hline & $b$ & $t$ & $b$ & $t$ & $\boldsymbol{b}$ & $t$ & & $b$ & $t$ \\
\hline \multicolumn{10}{|l|}{ Females $^{a}$} \\
\hline Cohort & .284 & $10.04 * * *$ & -.205 & $-2.02 *$ & .269 & 11.67 & $* \star *$ & -.013 & -0.16 \\
\hline Cohort $^{2}$ & -.020 & $-6.42 * * *$ & .034 & $3.11^{* *}$ & -.019 & -8.04 & $* \star *$ & .009 & 1.13 \\
\hline Mother Worked ${ }^{\mathrm{b}}$ & .186 & $11.13^{* * *}$ & .185 & $11.07^{* * *}$ & .193 & 15.88 & $* * *$ & .192 & $15.83^{* * *}$ \\
\hline Education (years) & .050 & $14.29^{* * *}$ & -.037 & -1.86 & .054 & 22.86 & $* * *$ & -.004 & -0.25 \\
\hline Family Income ${ }^{c}$ & .050 & $5.22 * * *$ & .050 & $5.17^{* * *}$ & .058 & 8.51 & $* * *$ & .058 & $8.48^{* * *}$ \\
\hline Part-Time Worker $^{d}$ & -.210 & $-7.52 * * *$ & -.209 & $-7.49 * * *$ & -.188 & -9.88 & $* * *$ & -.187 & $-9.85^{* * *}$ \\
\hline Unemployed $^{d}$ & -.219 & $-4.56^{* * *}$ & -.218 & $-4.55^{* * *}$ & -.143 & -5.06 & $* * *$ & -.142 & $-5.02 * * *$ \\
\hline Homemaker $^{d}$ & -.570 & $-25.37^{* * *}$ & -.569 & $-25.36 * * *$ & -.537 & -31.28 & $* * *$ & -.536 & $-31.20 * * *$ \\
\hline Retired $^{d}$ & -.314 & $-11.05 * * *$ & -.309 & $-10.87^{* * *}$ & -.215 & -11.06 & $* * *$ & -.212 & $-10.85^{* * *}$ \\
\hline Marr. Sp. Not Emp. ${ }^{\text {e }}$ & -.056 & -2.23 * & -.052 & $-2.08 *$ & -.060 & -3.54 & $* * *$ & -.059 & $-3.48^{* * *}$ \\
\hline Marr. Sp. Emp. ${ }^{e}$ & -.180 & $-8.51 * * *$ & -.181 & $-8.55^{* * *}$ & -.151 & -10.42 & $* * *$ & -.151 & $-10.42 * * *$ \\
\hline Education $\times$ Cohort & & & .044 & $4.97^{* * *}$ & & & & .026 & $3.78^{* * *}$ \\
\hline Education $\times$ Cohort $^{2}$ & & & -.005 & $-5.09 * * *$ & & & & -.003 & $-3.67^{* * *}$ \\
\hline Age Group Variance & 0.038 & & 0.037 & & 0.034 & & & 0.036 & \\
\hline Year Variance & 0.090 & & 0.093 & & 0.122 & & & 0.122 & \\
\hline Individual $N$ & 12,662 & & 12,662 & & 25,446 & & & 25,446 & \\
\hline \multicolumn{10}{|l|}{ Males $^{a}$} \\
\hline Cohort & .327 & $8.75^{* * *}$ & .134 & 1.22 & .264 & 9.44 & $* * *$ & .014 & 0.17 \\
\hline Cohort $^{2}$ & -.022 & $-5.65^{* * *}$ & -.006 & -0.47 & -.016 & -5.66 & $* * *$ & .004 & 0.50 \\
\hline Mother Worked & .226 & $12.04^{* * *}$ & .226 & $12.02^{* * *}$ & .247 & 18.07 & $* * *$ & .246 & $17.97^{* * *}$ \\
\hline Education (years) & .045 & 13.26 *** & .000 & -0.01 & .045 & 18.98 & $* * *$ & -.017 & -1.04 \\
\hline Family Income ${ }^{c}$ & .034 & $3.39 * * *$ & .035 & $3.47^{* * *}$ & .042 & 5.86 & $\star * *$ & .043 & 5.89 *** \\
\hline Part-Time Worker ${ }^{d}$ & .087 & 1.70 & .088 & 1.72 & .041 & 1.22 & & .042 & 1.25 \\
\hline Unemployed $^{d}$ & .035 & 0.86 & .040 & 0.97 & .065 & 2.27 & & .069 & 2.43 * \\
\hline Homemaker $^{d}$ & .048 & 1.05 & .045 & 0.99 & -.002 & -0.05 & & -.006 & -0.15 \\
\hline Retired $^{d}$ & .088 & $2.66^{* *}$ & .089 & $2.66 * *$ & .084 & 3.69 & $* * *$ & .083 & $3.63^{* * *}$ \\
\hline Marr. Sp. Not Emp. ${ }^{\text {e }}$ & -.302 & $-12.88^{* * *}$ & -.300 & $-12.81 * * *$ & -.254 & -14.88 & $* * *$ & -.252 & $-14.76^{* * *}$ \\
\hline Marr. Sp. Emp. ${ }^{e}$ & .137 & $5.50^{* * *}$ & .138 & $5.53^{* * *}$ & .124 & 7.17 & $* * *$ & .124 & 7.19 *** \\
\hline Education $x$ Cohort & & & .017 & 1.90 & & & & .023 & 3.23 ** \\
\hline Education $\times$ Cohort $^{2}$ & & & -.001 & -1.52 & & & & -.002 & $-2.56 *$ \\
\hline Age Group Variance & 0.067 & & 0.067 & & 0.042 & & & 0.043 & \\
\hline Year Variance & 0.115 & & 0.115 & & 0.138 & & & 0.138 & \\
\hline Individual $N$ & 10,311 & & 11,027 & & 20,657 & & & 20,657 & \\
\hline
\end{tabular}

${ }^{a}$ Dummy variable controls for nation not listed. ${ }^{b}$ Mother did not work omitted. ${ }^{c}$ Standardized within country. ${ }^{d}$ Full-time work omitted.

${ }^{\mathrm{e}}$ Unmarried omitted.

${ }^{*} p<.05^{* *} p<.01{ }^{* * *} p<.001$ 
More important for testing the diffusion hypothesis, the second model includes the interaction of education with cohort and cohort squared (again for the same seven nations). Differences in the effects of education, as represented by the interaction terms, fit the curvilinear pattern predicted by the diffusion hypothesis. The significant positive cohort interaction term and the significant negative cohort squared interaction term indicate that the effects of education initially increase across cohorts but eventually peak and decline. Calculations from the interaction coefficients indicate that the peak education effect occurs for the 1944 cohort.

The next two models in Table 2 use the sample of 19 nations with at least two time points. The additive determinants in the third model for the larger sample of nations are similar to those for the smaller sample. In the last model, the education by cohort interactions are again significant and in the predicted direction, although they are somewhat smaller than in the model for the smaller sample of nations. The education by cohort coefficients of $0.026(t=3.78)$ and $-.003(t=-3.67)$ are about half the size of the coefficients of $0.044(t=4.97)$ and $-0.005(t=-5.09)$ for the smaller group of nations. Both groups of nations show effects of education that rise and reverse, but the effects are weaker for the larger sample.

The bottom panels of Table 2 present the same models for males. The coefficients for males differ from those for females in several ways. For men, having a working spouse increases gender egalitarianism, while having a non-working spouse lowers egalitarianism. Also, own employment status has only weak influences for men. Of key importance, the education by cohort interactions have the predicted signs for men, but the interactions are smaller than for women in the more homogenous set of seven nations and fail to reach statistical significance. Calculations from the coefficients indicate that, whereas the reversal occurs for female cohorts born in 1944, it occurs for male cohorts born in 1985. In these nations, new gender views appear to have spread among men later than among women. In contrast, the interaction coefficients for the larger group of nations differ little between men and women.

To present the interaction effects visually, Figure 1 graphs the female and male slopes of education for each cohort as implied by the interaction models and does so separately for the two sets of nations. The four curves depict rising slopes for education that reverse, but the curve for females in the smaller sample has the highest peak and largest drop, and indicates both the greatest divisions and most convergence. For the youngest cohorts, the effects of education for women in the smaller, three-year sample of nations drops closest to zero. 


\section{Figure 1: Predicted education slope for males and females by cohort and nation group}

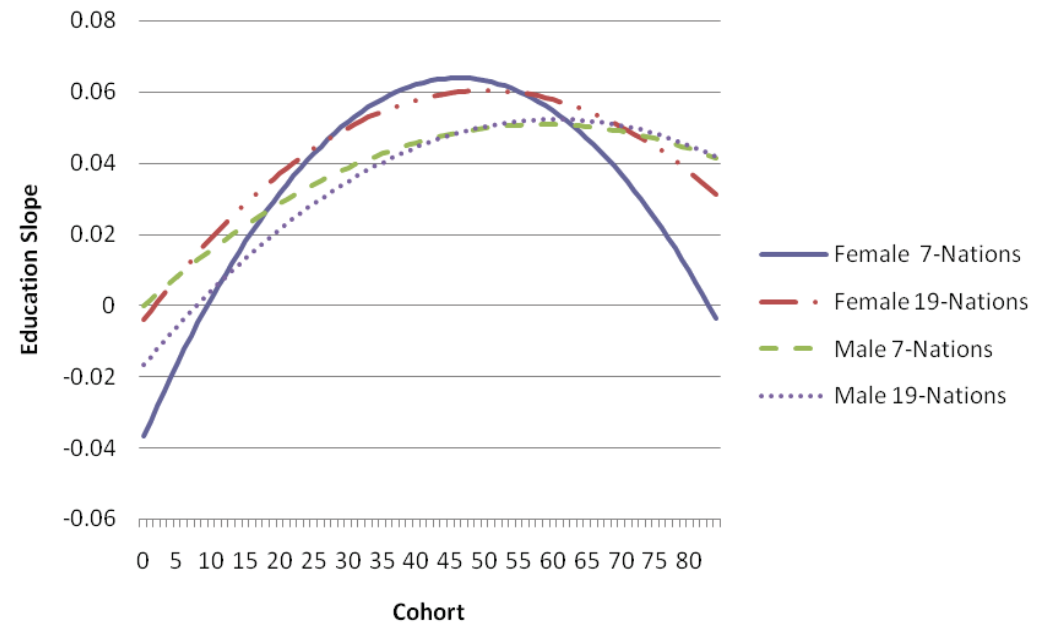

The models for the larger sample of nations, although supporting the diffusion hypothesis, mix Western nations and eastern European nations with diverse economic, social, and political backgrounds. Table 3 controls somewhat for this diversity by estimating models separately for Western nations and eastern European nations. The regions differ in a variety of dimensions - national income, communist history, gender discrimination, cultural history-that cannot be separated with the small number of nations. Still, differences in the models across these two regions help to identify where diffusion of GE has occurred most clearly. 
Table 3: Unstandardized coefficients and $t$ values for multilevel models of gender egalitarianism with year and age group random effects, by region

\begin{tabular}{|c|c|c|c|c|c|c|c|c|c|c|}
\hline \multirow[b]{3}{*}{ Predictors $^{a}$} & \multicolumn{5}{|c|}{ Females } & \multicolumn{5}{|c|}{ Males } \\
\hline & \multicolumn{2}{|c|}{$\begin{array}{l}\text { Western } \\
\text { Nations }\end{array}$} & \multicolumn{3}{|c|}{$\begin{array}{c}\text { Eastern European } \\
\text { Nations }\end{array}$} & \multicolumn{2}{|c|}{$\begin{array}{l}\text { Western } \\
\text { Nations }\end{array}$} & \multicolumn{3}{|c|}{$\begin{array}{c}\text { Eastern European } \\
\text { Nations }\end{array}$} \\
\hline & $b$ & $t$ & $b$ & $t$ & & $b$ & $t$ & $b$ & $t$ & \\
\hline Cohort & 0.008 & 0.08 & 0.269 & 1.98 & * & 0.033 & 0.33 & 0.000 & 0.00 & \\
\hline Cohort $^{2}$ & 0.014 & 1.37 & -0.024 & -1.72 & & 0.008 & 0.72 & 0.000 & -0.02 & \\
\hline Mother Worked $^{\mathrm{b}}$ & 0.207 & $14.47^{* * *}$ & 0.172 & 7.71 & $\star \star *$ & 0.249 & $15.65^{* * *}$ & 0.233 & 8.86 & $\star * \star$ \\
\hline Education (years) & 0.010 & 0.54 & 0.103 & 3.51 & $\star \star * \star$ & -0.011 & -0.57 & 0.025 & 0.80 & \\
\hline Family Income $^{c}$ & 0.065 & $7.91^{* * *}$ & 0.027 & 2.28 & * & 0.053 & $6.08^{* * *}$ & 0.024 & 1.87 & \\
\hline Part-Time Worker ${ }^{d}$ & -0.232 & $-10.92 * * *$ & -0.161 & -3.62 & $* * *$ & 0.075 & 1.95 & -0.031 & -0.45 & \\
\hline Unemployed $^{d}$ & -0.260 & $-6.60 * * *$ & 0.010 & 0.26 & & 0.054 & 1.47 & 0.098 & 2.19 & * \\
\hline Homemaker $^{d}$ & -0.628 & $-31.58 * * *$ & -0.314 & -8.66 & $* * *$ & -0.034 & -0.71 & -0.097 & -1.29 & \\
\hline Retired $^{d}$ & -0.292 & $-11.84 * * *$ & -0.148 & -4.57 & $* * *$ & 0.104 & $3.76^{* * *}$ & 0.013 & 0.34 & \\
\hline Marr. Sp. Not Emp. ${ }^{e}$ & -0.049 & -2.23 * & -0.035 & -1.34 & & -0.320 & $-15.76 * * *$ & -0.094 & -3.07 & $* *$ \\
\hline Marr. Sp. Emp. ${ }^{\text {e }}$ & -0.160 & $-8.98^{* * *}$ & -0.073 & -3.02 & $* *$ & 0.165 & $8.01^{* * *}$ & 0.096 & 3.14 & $* *$ \\
\hline Education $x$ Cohort & 0.025 & 3.08 ** & -0.021 & -1.69 & & 0.024 & 2.95 ** & -0.001 & -0.09 & \\
\hline Education $\times$ Cohort $^{2}$ & -0.003 & $-3.45^{* * *}$ & 0.002 & 1.66 & & -0.002 & $-2.59 * *$ & 0.001 & 0.39 & \\
\hline Age Group Variance & 0.037 & & 0.045 & & & 0.017 & & 0.000 & & \\
\hline Year Variance & 0.100 & & 0.222 & & & 0.090 & & 0.207 & & \\
\hline Individual $N$ & 17,751 & & 8,859 & & & 15,164 & & 6,555 & & \\
\hline
\end{tabular}

${ }^{a}$ Dummy variable controls for nation not listed. ${ }^{b}$ Mother did not work omitted. ${ }^{c}$ Standardized within country. ${ }^{d}$ Full-time work omitted.

${ }^{\mathrm{e}}$ Unmarried omitted.

${ }^{*} p<.05^{* *} p<.01^{* * *} p<.001$

As shown in Table 3, the two regions differ in the pattern of the education by cohort interactions. The models for the Western nations are similar to the models over all in Table 2. In contrast, the interaction terms for eastern European nations in Table 3 fail to reach statistical significance. Figure 2 graphs the education by cohort slopes predicted by the models for males and females in both regions. The reversal in education effects shows clearly for the Western nations. Likely reflecting randomness, the curves for eastern European nations fail to show the rise and decline in the effects of education that the Western nations do. These results suggest little evidence of GE diffusion across levels of education in eastern Europe. 


\section{Figure 2: Predicted education slope for males and females by cohort and region}

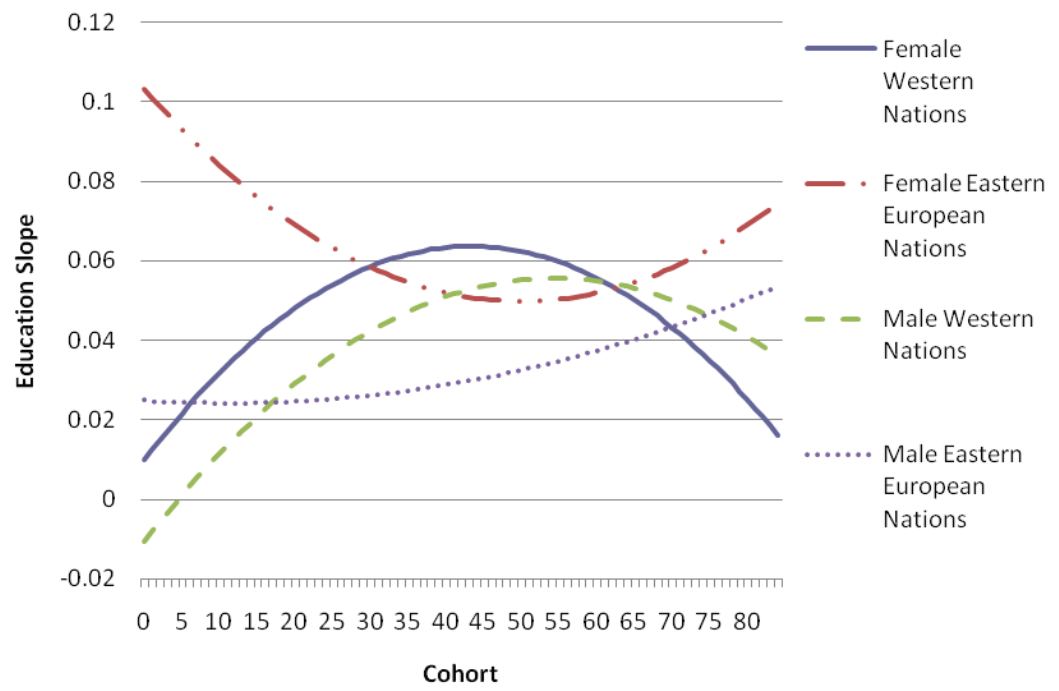

\subsection{Sensitivity Checks}

Checks of the sensitivity of the results to influential nations strengthen the findings for women but suggest less reliability in the results for men. The models in Table 4 focus on the education by cohort interactions for the smaller groups of nations with data on three time points. The largely Western nations in this group are those where diffusion has occurred most clearly. For all seven of these nations, the female education by cohort coefficient of $0.044(t=4.97)$ and education by cohort squared coefficient of -0.005 $(t=-5.09)$ match those presented earlier. Based on jackknife procedures in which models are estimated with one of the nations deleted, the table lists seven more sets of interaction coefficients, first for females and then for males. For females, deleting West Germany and Hungary reduces the coefficients, while deleting Great Britain and the United States increases the coefficients. Yet, the interaction coefficients remain significant and similar to those for the full set of nations. The checks demonstrate the robustness of the interactions. 
Table 4: Unstandardized coefficients and $t$ values for multilevel coefficients and $t$ values for interaction terms in jackknifed models of gender egalitarianism

\begin{tabular}{lcccccc}
\hline & \multicolumn{2}{c}{ Education X Cohort } & \multicolumn{3}{c}{ Education x Cohort } \\
& $\boldsymbol{b}$ & $\boldsymbol{t}$ & & & $\boldsymbol{b}$ & $\boldsymbol{t}$ \\
\hline Females & & & & & & \\
All Nations & 0.044 & 4.97 & $* * *$ & -0.005 & -5.09 & $* * *$ \\
Delete West Germany & 0.030 & 3.25 & $* *$ & -0.003 & -3.57 & $* * *$ \\
Delete Great Britain & 0.049 & 5.30 & $* * *$ & -0.005 & -5.36 & $* * *$ \\
Delete US & 0.061 & 5.92 & $* * *$ & -0.006 & -5.72 & $* * *$ \\
Delete Austria & 0.046 & 5.00 & $* * *$ & -0.005 & -5.02 & $* * *$ \\
Delete Hungary & 0.032 & 3.23 & $* *$ & -0.004 & -3.77 & $* * *$ \\
Delete Ireland & 0.037 & 3.89 & $* * *$ & -0.004 & -3.86 & $* * *$ \\
Delete Netherlands & 0.047 & 5.00 & $* * *$ & -0.005 & -5.08 & $* * *$ \\
& & & & & & \\
Males & & & & & & \\
All Nations & 0.017 & 1.90 & & -0.001 & -1.52 & \\
Delete West Germany & 0.006 & 0.64 & & -0.000 & -0.40 & \\
Delete Great Britain & 0.015 & 1.57 & & -0.001 & -1.01 & \\
Delete US & 0.027 & 2.62 & $* *$ & -0.002 & -2.19 & $*$ \\
Delete Austria & 0.023 & 2.34 & $*$ & -0.002 & -2.09 & $*$ \\
Delete Hungary & 0.014 & 1.35 & & -0.001 & -1.29 & \\
Delete Ireland & 0.023 & 2.29 & $*$ & -0.002 & -1.78 & \\
Delete Netherlands & 0.009 & 0.92 & & -0.001 & -0.60 & \\
\hline
\end{tabular}

${ }^{*} p<.05{ }^{* *} p<.01{ }^{* * *} p<.001$

For men, the coefficients in Table 4 show that individual nations affect the results in non-trivial ways. Among all seven nations, the coefficients of $0.017(t=1.90)$ for education by cohort and $-0.001(t=-1.52)$ for education by cohort squared show effects that are smaller than for women and provide limited support of the diffusion hypothesis. However, deleting the United States or Austria raises both interaction coefficients to statistical significance. This suggests that the diffusion pattern of change in the effects of education may hold across most of the nations but is weakened by the special experiences in one or two nations. The limited diffusion of GE among males in the United States and Austria does not appear typical of the other nations. Thus, these checks demonstrate less reliability of results for males. To a large extent, the pattern of diffusion is weaker and less consistent for males than for females.

Checks on alternative measures of education (not presented in the tables) similarly reveal greater robustness for the female than for the male results. Other measures include 1) educational degree rather than years of education completed, 2) educational 
degree standardized within nations, and 3) years of education completed standardized within nations. For women, the educational degree and standardized measures continue to show significant cohort interactions, at least among Western nations. For men, the other measures tend to produce weaker results. For example, within-nation standardization of the measure of education years reduces the interactions to below significance for the sample of nations with three time points. This again suggests less robustness in the interactions for men.

\section{Conclusion}

Based on the analysis of a diverse set of European nations plus the United States, Australia, and New Zealand, the adoption of gender egalitarian views occurred steadily across cohorts over much of the twentieth century. Less obviously, however, the results also show that adoption reflects nonlinear changes in the influence of education and the strength of socioeconomic cleavages. The effects of education become stronger across older cohorts as attitudes toward gender equality shift from largely unfavorable to favorable among women with greater education (and likely stronger commitment to work and career). Among the most recent cohorts, however, the effects of education become weaker as favorable attitudes spread widely through the population and socioeconomic differences decline in importance. These results replicate the results reported by Pampel (2011) and Fischer and Hout (2006) for the United States, but with a wider set of nations.

Theories of both structural position and value change, though incomplete on their own, play a role in explaining the pattern of results. Structural changes that increase education and related work and career opportunities for women provide the impetus to adopt egalitarianism by strengthening direct interests in equality among certain segments of the population. Value changes among other groups of women with less education (but still with interests in gender equality) occur later through processes of diffusion. According to the diffusion theory, both structural and cultural mechanisms contributed to the rising support for gender equality over the last century but did so in sequence.

The evidence is strong and robust for women in Western nations but is less supportive for men and for eastern European nations. Men not only hold less egalitarian views than women but also show less responsiveness to social change. In Western nations, the effects of education on gender egalitarianism increase and decrease for men as they do for women but appear highly influenced by a few nations and by the particular measure of education. Gender egalitarianism among recent cohorts thus depends more on level of education among men than among women. This difference in 
patterns of change suggests that diffusion has moved faster and farther among women than among men and qualifies theoretical claims about diffusion. The diffusion process best fits women more than men likely because of their stronger interests in and benefits from equality. Since the advantages of an innovation increase the speed at which it is adopted (Rogers 2003), the gains to women relative to men lead to quicker diffusion of gender egalitarianism among women relative to men.

Neither men nor women show a clear diffusion pattern in eastern European nations. Numerous structural, political, cultural, and historical characteristics may contribute for the differences in patterns and trends in gender egalitarianism. More complete attention to the special circumstances and forces affecting gender equality in the former-Communist nations of Eastern Europe is needed to explore the sources of the differences. The theories evaluated here focus on structural change in education and work opportunities for women and on values related to economic security in affluent nations. However, consideration of other factors not highlighted by these theories are needed to better understand the experiences of the Eastern European nations. This study describes the scope of the diffusion findings but is limited in its ability to explain the cross-national differences.

The empirical approach used here to specify and test hypotheses about the sources of change in gender egalitarianism has several advantages. Examining differences across cohorts rather than years, modeling the varying effects of education on gender egalitarianism rather than just the level of gender egalitarianism, and testing nonlinear predictions of an integrative diffusion theory all help extend the literature in new directions. Making comparisons across cohorts builds on other studies (Brewster and Padovic 2000; Brooks and Bolzendahl 2004; Ciabattari 2001; Schnittker, Freese, and Powell 2003; Wilkie 1993) but also more fully exploits the potential for change to occur across groups that are born and socialized in different historical periods. Modeling interactions between cohort and education captures both the diffusion of gender egalitarianism and the importance of cohort sources of social change.

The data and methods used to evaluate the approach, however, present some limitations. First, the data allow for only the indirect study of diffusion. The patterns of change in the education effects are consistent with initial adoption of gender egalitarianism by innovative groups and the later diffusion to other groups. Indeed, the predictions of nonlinear interactions of cohort and education are highly falsifiable. Yet, other types of data and forms of analysis are needed to more directly validate claims about diffusion. For example, better measures of the historical characteristics of cohorts over the past century can extend the approach. Gathering cohort-based measures of the economic, political, social, and cultural environment-particularly as they relate to education, work, and earnings opportunities of women-from historical sources presents a daunting task. Even so, future research can use such data to provide 
additional tests of predictions that the context of gender equality relates nonlinearly to the effects of the determinants of gender egalitarianism.

Second, the inability to measure SES and family characteristics of older cohorts at the time of young adulthood rather than at older ages compromises the tests. Current education, the key determinant in the analysis, reflects past education better than current employment, job characteristics, income, and family status reflect past characteristics. Measures of other socioeconomic characteristics would improve the models, but the lack of long-term longitudinal data for multiple cohorts during the formative years of youth and young adulthood warrants the reliance on education.

Third, the gender egalitarian items used here are only a subset of possible measures, and one cannot assume that they give the same results as other sets of measures would. The items on work/family issues faced by women give little attention to changes in men's roles and the need for restructuring gender roles. Studies need to do more to organize the diverse measures used in the literature into multiple dimensions of gender egalitarianism and compare results across the different dimensions.

Some of these limitations can be overcome with the release of the 2012 ISSP data, which offers a fourth module on family, work, and gender roles. The new 2012 surveys will extend the period of study for nations that participated in previous surveys and likely add some new nations to the sample. Going beyond the basic results reported here, the new surveys will allow for better measures of diffusion and a more detailed comparison of the nations of Western and Eastern Europe. 


\section{References}

Alwin, D.F., Braun, M., and Scott, J. (1992). The separation of work and the family: Attitudes towards women's labour-force participation in Germany, Great Britain, and the United States. European Sociological Review 8(1): 13-37.

Amato, P.R. and Booth, A. (1995). Changes in gender role attitudes and perceived marital quality. American Sociological Review 60(1): 58-66. doi:10.2307/2096345.

Baxter, J. and Kane, E.W. (1995). Dependence and independence: A cross-national analysis of gender inequality and gender attitudes. Gender and Society 9(2): 193-215. doi:10.1177/089124395009002004.

Bolzendahl, C.I. and Myers, D.J. (2004). Feminist attitudes and support for gender equality: Opinion change in women and men 1974-1998. Social Forces 83(2): 759-790. doi:10.1353/sof.2005.0005.

Brewster, K. and Padavic, I. (2000). Change in gender ideology, 1977-1996: The contributions of intracohort change and population turnover. Journal of Marriage and the Family 62(2): 477-487. doi:10.1111/j.17413737.2000.00477.x.

Brooks, C. and Bolzendahl, C.I. (2004). The transformation of U.S. gender role attitudes: Cohort replacement, social-structural change, and ideological learning. Social Science Research 33(1): 106-133. doi:10.1016/S0049-089X(03)00041-3.

Carter, J.S., Corra, M., and Carter, S.K. (2009). The interaction of race and gender: Changing gender-role attitudes, 1974-2006. Social Science Quarterly 90(1): 196-211. doi:10.1111/j.1540-6237.2009.00611.x.

Cha, Y. and Thébaud, S. (2009). Labor markets, breadwinning, and beliefs: How economic context shapes men's gender ideology. Gender and Society 23(2): 215-243. doi:10.1177/0891243208330448.

Charles, M. and Bradley, K. (2002). Equal but separate? A cross-national study of sex segregation in higher education. American Sociological Review 67(4): 573-599. doi: $10.2307 / 3088946$.

Ciabattari, T. (2001). Changes in men's conservative gender ideologies: Cohort and period influences. Gender \& Society 15(4): 574-591. doi:10.1177/ 089124301015004005 . 
Firebaugh, G. (1992). Where does social change come from? Population Research and Policy Review 11(1): 1-20. doi:10.1007/BF00136392.

Fischer, C.S. (1978). Urban-to-rural diffusion of opinions in contemporary America. American Journal of Sociology 84(1): 151-159. doi:10.1086/226744.

Fischer, C.S. and Hout, M. (2006). Century of difference: How America changed in the last one hundred years. New York: Russell Sage Foundation.

Glass, J. (1992). Housewives and employed wives: Demographic and attitudinal change 1972-1986. Journal of Marriage and the Family 54(3): 559-569. doi: $10.2307 / 353242$.

Goldscheider, F., Oláh, L.S., and Puur, A. (2010). Reconciling studies of men's gender attitudes and fertility: Response to Westoff and Higgins. Demographic Research 22(8): 189-198. http://www.demographic-research.org/Volumes/Vol22/8/228.pdf. doi:10.4054/DemRes.2010.22.8.

Henz, U. (2008). Gender roles and values of children: Childless couples in East and West Germany. Demographic Research 19(39): 1451-1500. http://www.demographic-research.org/Volumes/Vol19/39/19-39.pdf. doi:10.4054/DemRes.2008.19.39.

Huber, J. (1990). Macro-micro links in gender stratification: 1989 Presidential Address. American Sociological Review 55(1): 1-10. doi:10.2307/2095699.

Huber, J. and Spitze, G. (1981). Wives' employment, household behaviors, and sex-role attitudes. Social Forces 60(1): 150-169. doi:10.2307/2577937.

Inglehart, R. (1989). Culture shift in advanced industrial society. Princeton, NJ: Princeton University Press.

Inglehart, R. and Baker, W.E. (2000). Modernization, cultural change, and the persistence of traditional values. American Sociological Review 65(1): 19-51. doi: $10.2307 / 2657288$.

Inglehart, R. and Norris, P. (2003). Rising tide: Gender equality and cultural change. New York: Cambridge University Press.

International Social Survey Program (ISSP). (2011). General information [electronic resource]. http://www.issp.org.

Jackson, R.M. (1998). Destined for equality: The inevitable rise of women's status. Cambridge: Harvard University Press. 
Kane, E.W. and Kyyrö, E.K. (2001). For whom does education enlighten? Race, gender, education, and beliefs about social inequality. Gender \& Society 15(5): 710-733. doi:10.1177/089124301015005005.

Kane, E.W. and Sanchez, L. (1994). Family status and criticism of gender inequality at home and at work. Social Forces 72(4): 1079-1102. doi:10.2307/2580293.

Kaufman, G. (2000). Do gender role attitudes matter? Journal of Family Issues 21(1): 128-134. doi:10.1177/019251300021001006.

Lesthaeghe, R. (2010). The unfolding story of the second demographic transition. Population and Development Review 36(2): 211-251. doi:10.1111/j.17284457.2010.00328.x.

Lesthaeghe, R. and Surkyn, J. (1988). Cultural dynamics and economic theories of fertility change. Population and Development Review 14(1): 1-45. doi:10.2307/1972499.

Mason, K.O. and Lu, Y-H. (1988). Attitudes toward women's familial roles: Changes in the United States 1977-1985. Gender \& Society 2(1): 39-57. doi:10.1177/089124388002001004.

Montgomery, M.R. and Casterline, J.B. (1993). The diffusion of fertility control in Taiwan: Evidence from pooled cross-section time-series models. Population Studies 47(3): 457-479. doi:10.1080/0032472031000147246.

Ohlander, J., Batalova, J., and Treas, J. (2005). Explaining educational influences on attitudes toward homosexual relations. Social Science Research 34(4): 781-799. doi:10.1016/j.ssresearch.2004.12.004.

Oláh, L.S. and Bernhardt, E. (2008). Sweden: Combining childbearing and gender equality. Demographic Research 19(28): 1105-1144. http://www.demographicresearch.org/volumes/vol19/28. doi:10.4054/DemRes.2008.19.28.

Pampel, F.C. (2011). Cohort changes in the socio-demographic determinants of gender egalitarianism. Social Forces 89(3): 961-982. doi:10.1353/sof.2011.0011.

Petersen, L.R. and Donnenwerth, G.V. (1998). Religion and declining support for traditional beliefs about gender roles and homosexual rights. Sociology of Religion 59(4): 353-371. doi:10.2307/3712122.

Plutzer, E. (1988). Work life, family life, and women's support of feminism. American Sociological Review 53(4): 640-649. doi:10.2307/2095855. 
Poole, K.T. and Zeigler, L.H. (1981). The diffusion of feminist ideology. Political Behavior 3(3): 229-256. doi:10.1007/BF00990097.

Rindfuss, R.R., Brewster, K.L., and Kavee, A.L. (1996). Women, work and children: Behavioral and attitudinal change in the United States. Population and Development Review 22(3): 457-482. doi:10.2307/2137716.

Rogers, E.M. (2003). Diffusion of innovations, Fifth Edition. New York: Free Press.

Ryder, N.B. (1965). The cohort as a concept in the study of social change. American Sociological Review 30(6): 843-861. doi:10.2307/2090964.

Schnittker, J., Freese, J., and Powell, B. (2003). Who are feminists and what do they believe? The role of generations. American Sociological Review 68(4): 607-622. doi:10.2307/1519741.

Scott, J., Alwin, D.F., and Braun, M. (1996). Generational changes in gender-role attitudes: Britain in a cross-national perspective. Sociology 30(3): 471-492. doi:10.1177/0038038596030003004.

Smith, T.W. (1985). Working wives and women's rights: The connection between the employment status of wives and the feminist attitudes of husbands. Sex Roles 12(5-6): 501-508. doi:10.1007/BF00288172.

Spitze, G. and Huber, J. (1980). Changing attitudes toward women's nonfamily roles: 1938 to 1978. Work and Occupations 7(3): 317-335. doi:10.1177/ 073088848000700303.

Strang, D. and Meyer, J.W. (1993). Institutional conditions for diffusion. Theory and Society 22(4): 487-511. doi:10.1007/BF00993595.

Strang, D. and Soule, S.A. (1998). Diffusion in organizations and social movements: From hybrid corn to poison pills. Annual Review of Sociology 24: 265-290. doi:10.1146/annurev.soc.24.1.265.

Thornton, A., and Young-DeMarco, L. (2001). Four decades of trends in attitudes toward family issues in the United States: The 1960s through the 1990s. Journal of Marriage and the Family 63(4): 1009-1037. doi:10.1111/j.17413737.2001.01009.x.

Treas, J. and Widmer, E.D. (2000). Married women's employment over the life course: Attitudes in cross-national perspective. Social Forces 78(4): 1409-1436. doi:10.2307/3006179. 
Weil, F.D. (1985). The variable effects of education on liberal attitudes: A comparativehistorical analysis of anti-semitism using public opinion survey data. American Sociological Review 50(4): 458-474. doi:10.2307/2095433.

Wilkie, J.R. (1993). Changes in U.S. men's attitudes toward the family provider role, 1972-1989. Gender \& Society 7(2): 261-279. doi:10.1177/ 089124393007002007.

Yang, Y. and Land, K.C. (2006). A mixed models approach to the age-period-cohort analysis of repeated cross-section surveys, with an application to data on trends in verbal test scores. Sociological Methodology 36(1): 75-97. doi:10.1111/ j.1467-9531.2006.00175.x.

Zuo, J. and Tang, S. (2000). Breadwinner status and gender ideologies of men and women regarding family roles. Sociological Perspectives 43(1): 29-43. 
Pampel: Cohort change, diffusion, and support for gender egalitarianism in cross-national perspective 